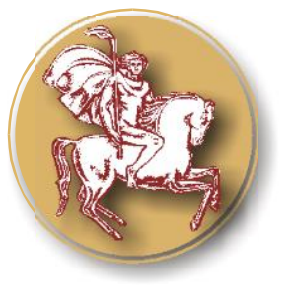

Trakia Journal of Sciences, No 3, pp 265-272, 2021

Copyright (C) 2021 Trakia University

Available online at:

http://www.uni-sz.bg

ISSN 1313-3551 (online)

doi:10.15547/tjs.2021.03.011

Original Contribution

\title{
INTERFACE TWO-CHANNEL PORTABLE SYSTEM FOR 24 HOUR REGISTRATION OF BREATHING AND NASAL CYCLE
}

\author{
A. Atanasov ${ }^{1 *}$, G. Arabadgiev1, P. Zagorchev ${ }^{2}$ \\ ${ }^{1}$ Medical Faculty, Trakia University, Stara Zagora, Bulgaria \\ ${ }^{2}$ Dental Faculty, University of Plovdiv, Plovdiv, Bulgaria
}

\begin{abstract}
The registration of respiration through the left and right nostrils simultaneously makes it possible to register the dynamics and periodicity of the nasal cycle. For this purpose, an interface two-channel portable system has been developed for 24-hour recording of breathing through the two nostrils separately. The portable system can be used for multifunctional medical examinations under any conditions in patients with various anatomical and physiological disorders of breathing, sleep, and consciousness.
\end{abstract}

Key words: nasal cycle, measurement, electronic device

\section{INTRODUCTION}

In human have two nostril passages. The airflow through the left and the right nostril are not symmetrical, due to anatomical and physiological factors. The physiological factors are related to spontaneous congestion and decongestion of the nasal venous sinuses, well known as nasal cycle $(1,2)$. The nasal cycle is related to autonomic nervous system, asymmetry in hemisphere blood flow and asymmetry of EEG brain activity (3-5). There are some indications that the nasal cycle is connected to the conscious states of the brain (6, $7)$. There are many methods for measurement and characterization of nasal cycle. The most applicable methods are rhinometry (8), use of portable spirometer (9), acoustic rhinometry (10), endoscopy and rhino-resistometry (11) and portable rhino-flowmetry (12). Some methods for temperature measurement of nasal airflow as flexible liquid crystal thermography (13) and mirror evaluation $(14,15)$ as well as portable nasal airflow monitor (16). More recent method for measuring and characterization of the nasal cycle is developed by Kahana-Zweig et al. (17), by using of pressure sensor

Correspondence to: A.T. Atanasov Trakia University- Stara Zagora, Medical Faculty, atanastod@abv.bg electronic device for each nostril separately. In our work we present a temperature method for registration of nasal cycles, by measuring the temperature of the respiratory air simultaneously, but separately through the left and right nostrils. This method has been used in previous measurements by the authors $(18,19)$.

\section{INTERFACE TWO-CHANNEL SYSTEM FOR RECORDING AND PROCESSING OF DATA RELATED TO THE BREATHING PROCESS THROUGH THE LEFT AND RIGHT NOSTRIL SEPARATELY AND REGISTRATION OF THE NASAL CYCLE}

The developed electronic device (prototype B2C, Sioptic, Plovdiv, Bulgaria) for measuring respiration through both nostrils is based on the reciprocal linear connection between the hydraulic resistance of the nasal cavities and the temperature difference between exhaled and inhaled air. The main steps in making and using the device are described below.

1. A module based on an anti-logarithmic differential amplifier with a gain of $\times 20$ is constructed. Designed to work with signals from microscopic thermistors (N-type, $10 \mathrm{kOhm}$ ) connected in a direct current bridge.

2. A two-channel 13-bit analog-to-digital converter has been developed, which converts the measured temperature values into digital 
form with the possibility of recording on a CD card. The data flow corresponding to the temperature changes is averaged for every 50 measurements, the arithmetic mean being fed at an interval of / $65 \pm 5 / \mathrm{ms}$ to a data acquisition controller.

3. An external data carrier / CD-card / is recorded in the following format (Table 1). The data accumulated in the CD-card are processed with the help of a computer in Excel Microsoft 365 environment - Figure 1(a).
ATANASOV A., et al. 4. A file DATALOG-2CH MODEL.xlsm has been prepared for a complete visualization of the research - Figure 1(b, c).

5. The methodology and the computer program allow the multi-hour records to be compressed, which facilitates their analysis and comparison 6. To illustrate the difference between recording respiration through both nostrils simultaneously and through both nostrils separately on Figure 2, Figure 3 and Figure 4 are shown some time-compressed records during a long night's sleep.

Table 1. Sample recording of the temperature difference of exhaled and inhaled air through the left and right nostril on the SD card.

\begin{tabular}{|l|l|l|l|l|}
\hline $\mathrm{N}$ & Time, $\mathrm{ms}$ & Ch1 (blue), mV-right nostril & $\begin{array}{l}\text { Ch2(red), mV-left } \\
\text { nostril }\end{array}$ & Time, min \\
\hline 1 & 1050 & 574 & 614 & 0.0175 \\
\hline 2 & 1210 & 599 & 643 & 0.0201 \\
\hline 3 & 1370 & 624 & 673 & 0.0228 \\
\hline 4 & 1540 & 648 & 700 & 0.0256 \\
\hline 5 & 1700 & 673 & 725 & 0.0283 \\
\hline 6 & 1860 & 699 & 751 & 0.0310 \\
\hline 7 & - & - & - & - \\
\hline
\end{tabular}
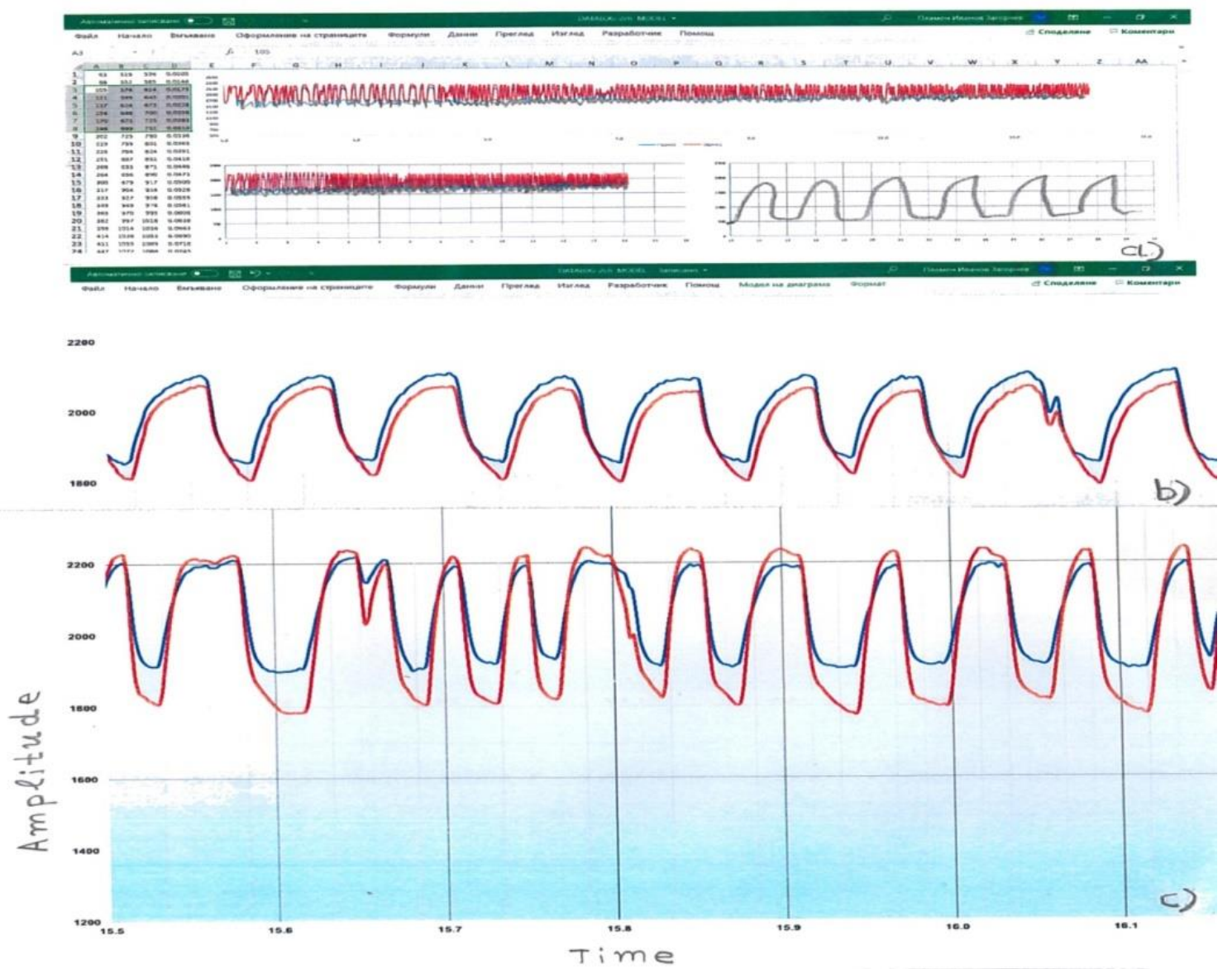

Figure 1. a). Data processing in Excel Microsoft 365 environment; b), c) Recording of breathing through the left and right nostrils in different modes. The gray line is a record of breathing through the left nostril. The black line is a record of the breathing of the right nostril. On the abscissa the time is plotted, and on the ordinate the amplitude of the respiration in units, which by calibration can be transformed into the temperature. 
ATANASOV A., et al.

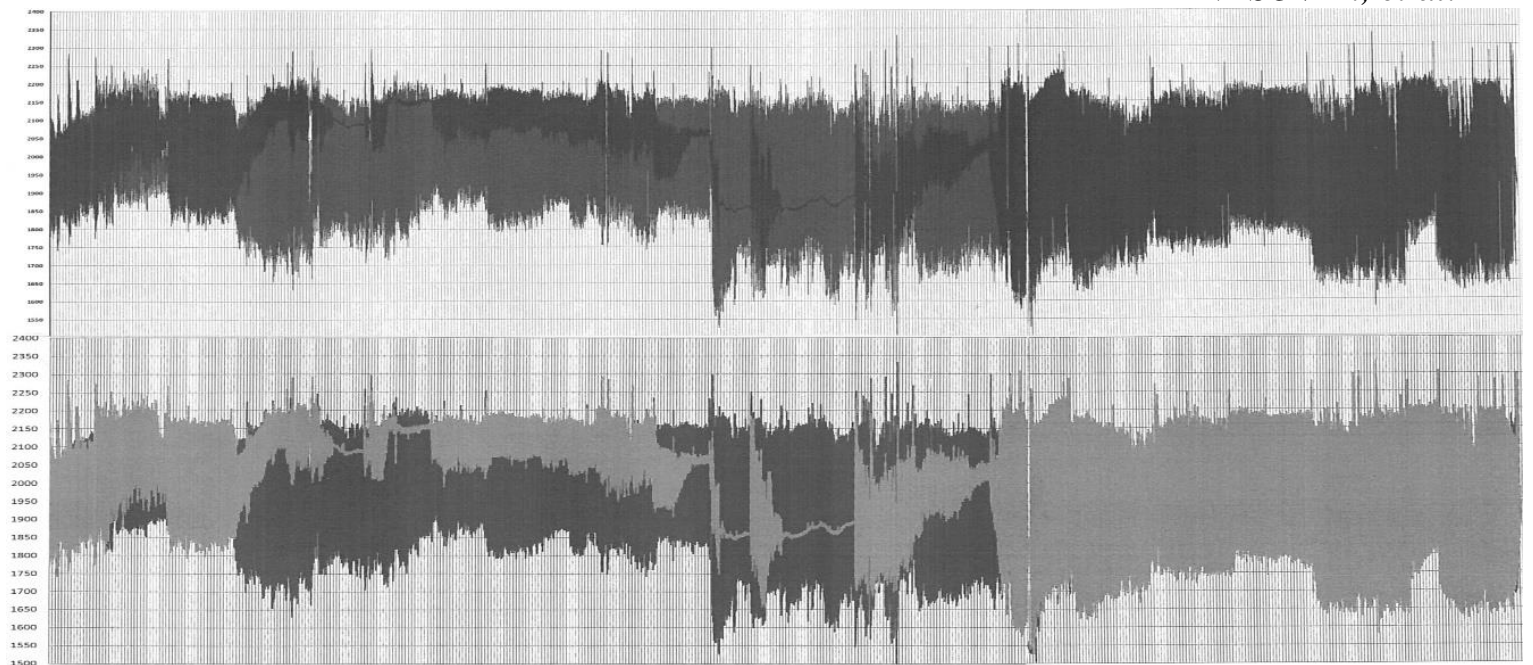

Figure 2. Time-compressed recording of breathing during 8-9 hours of sleep: recording through both nostrils (on top) and recording through the left and right nostrils (below). Legend: gray recordbreathing through the left nostril, dark record- breathing through the right nostril.

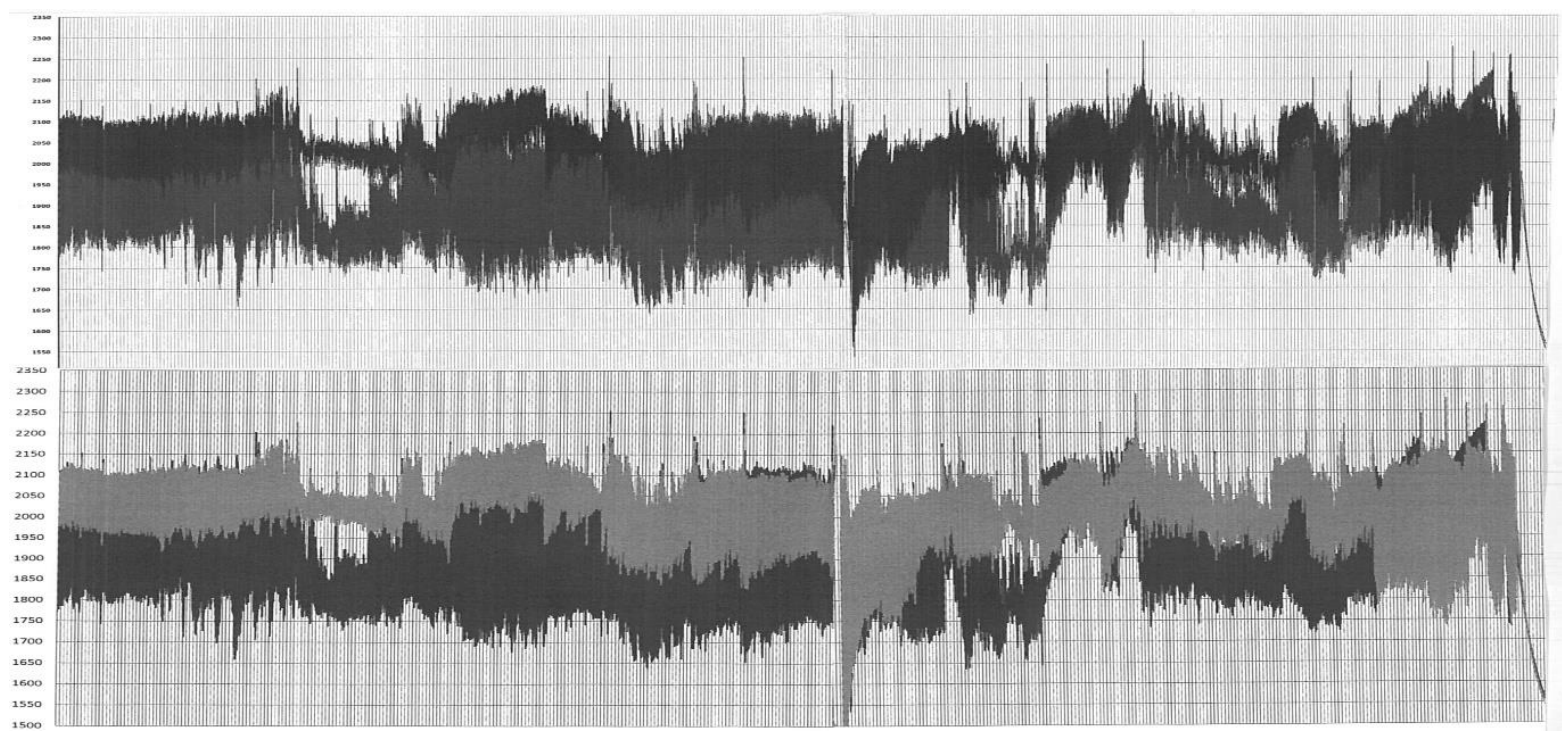

Figure 3. Time-compressed recording of breathing during 8-9 hours of sleep: recording through both nostrils (on top) and recording through the left and right nostrils (below). Legend: gray record- breathing through the left nostril, dark record- breathing through the right nostril.

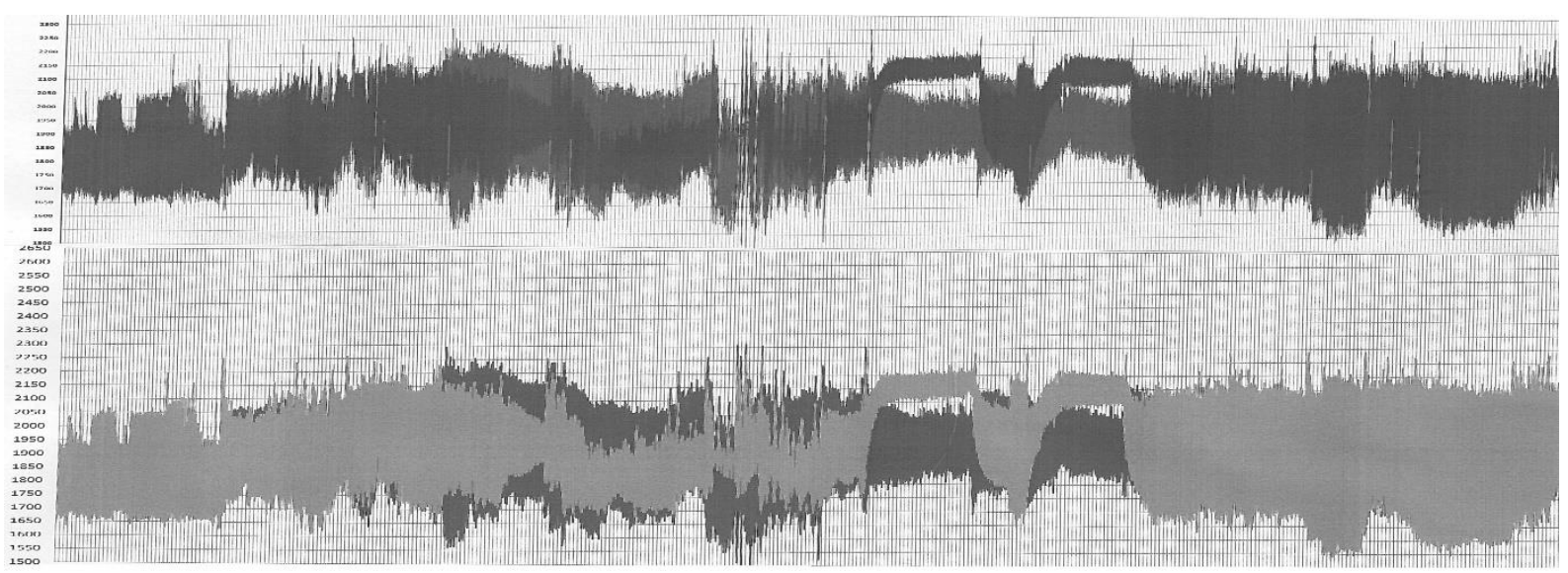

Figure 4. Time-compressed recording of breathing during 8-9 hours of sleep: recording through both nostrils (on top) and recording through the left and right nostrils (below). Legend: gray record- breathing through the left nostril, dark record- breathing through the right nostril. 


\section{FIELD OF APPLICATION OF THE TWO- CHANNEL INTERFACE SYSTEM FOR RESPIRATION SCAN}

1. Possibility for 24-hour scanning of breathing through both nostrils during the day and night in hospital, home and work conditions. The
ATANASOV A., et al. portable and light device of about 300 grams can be attached to the waist in a standard bag measuring $20 \mathrm{~cm} \times 15 \mathrm{~cm} \times 3 \mathrm{~cm}$ allows you to measure breathing at rest and movement, as well as any type of load on the body-physical and mental - Figure 5

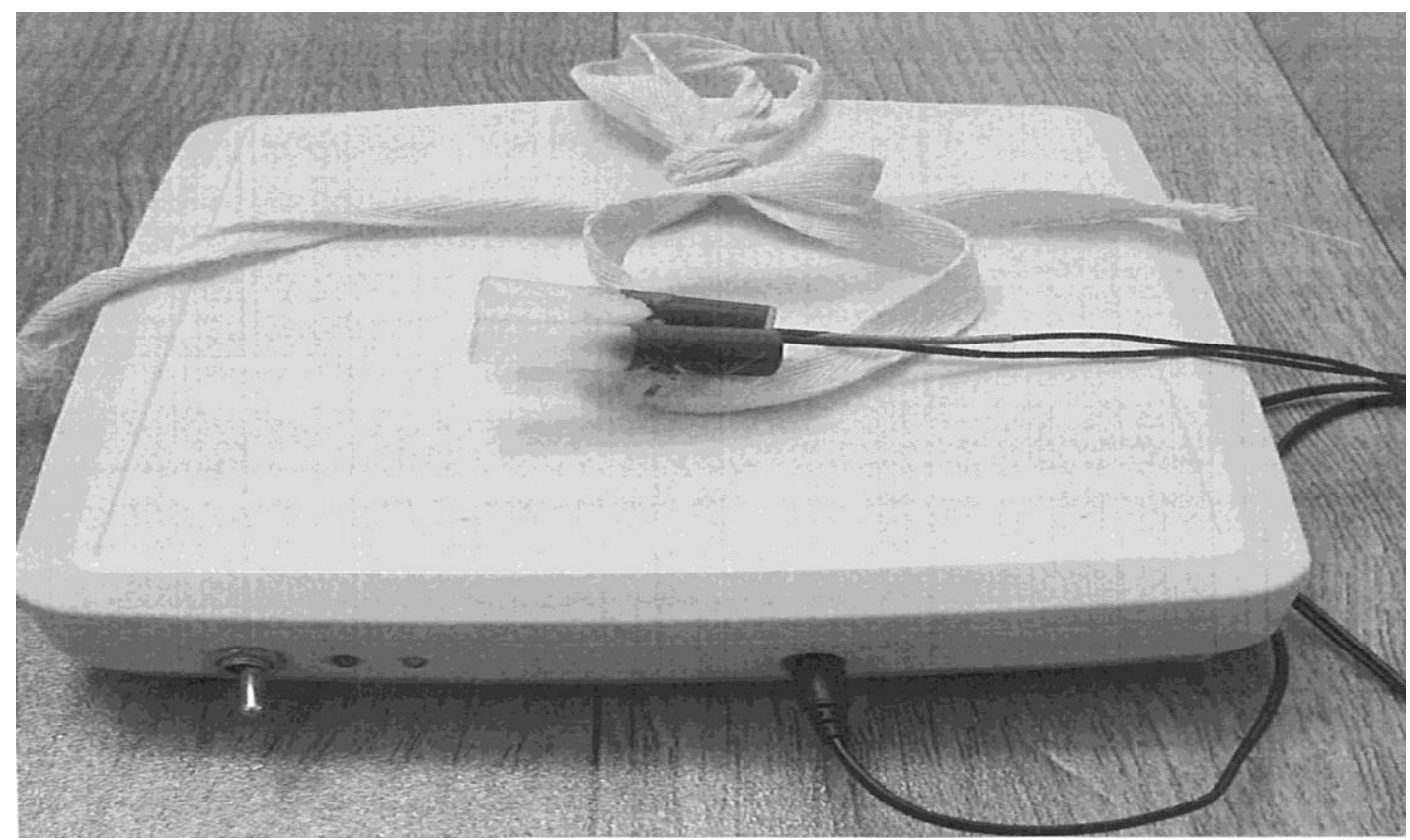

Figure 5. Photo of the portable two-channel interface system for 24-hour scanning of breathing through both nostrils.

2. Ability to scan the nasal cycle 24 hours a day $(17,20)$ and during sleep $(19,21)$.

3. It allows to scan the breathing and nasal cycle of patients in coma and unconsciousness with their own breathing $(6,7,22)$.

4. It allows to scan the breathing of patients with respiratory disorders, sleep, as well as patients with various anatomical problems of the nostrils $(23,24)$.

5 . It can be used in various psychological tests for diagnosis in people with various neurological diseases and cognitive impairment (25-27).

6. Allows registering REM stage during sleep $(18,19)$.

7. The simultaneous application of the method with EEG and EMG can contribute to the solution of various scientific tasks and problems $(2,22,28)$.

\section{PHYSICAL MODEL CONNECTING RESPIRATORY AMPLITUDE TO NASAL RESISTANCE}

The temperature difference of inhaled and exhaled air through the left and right nostrils due to the difference in norm is from $1^{\circ} \mathrm{C}$ to $3^{\circ} \mathrm{C}$ due to the different nasal resistance $(29,30)$. In the alternative change of the passability and the nasal resistance of the nostrils, the volumes of air and the temperature range (max-min temperature diapason) of air flows through them are alternately changed. Normally, due to the difference in nasal resistance, the difference in the volumes of respiratory air through the left and right nostrils is on average $1.0-3.5$ times. It changes the amount of heat exchanged with the air. The temperature difference is proportional to the amount of heat contained in the inhaled and exhaled air from the nostrils. The amplitude of the recording is proportional to the temperature difference between the exhaled warm and the inhaled cool air of the left and right nostrils (max-min temperature diapason). The connection of the amplitude of the recording with the difference of the temperature of the exhaled and inhaled air through the nostrils can be represented by the following physical model - Figure 6. 


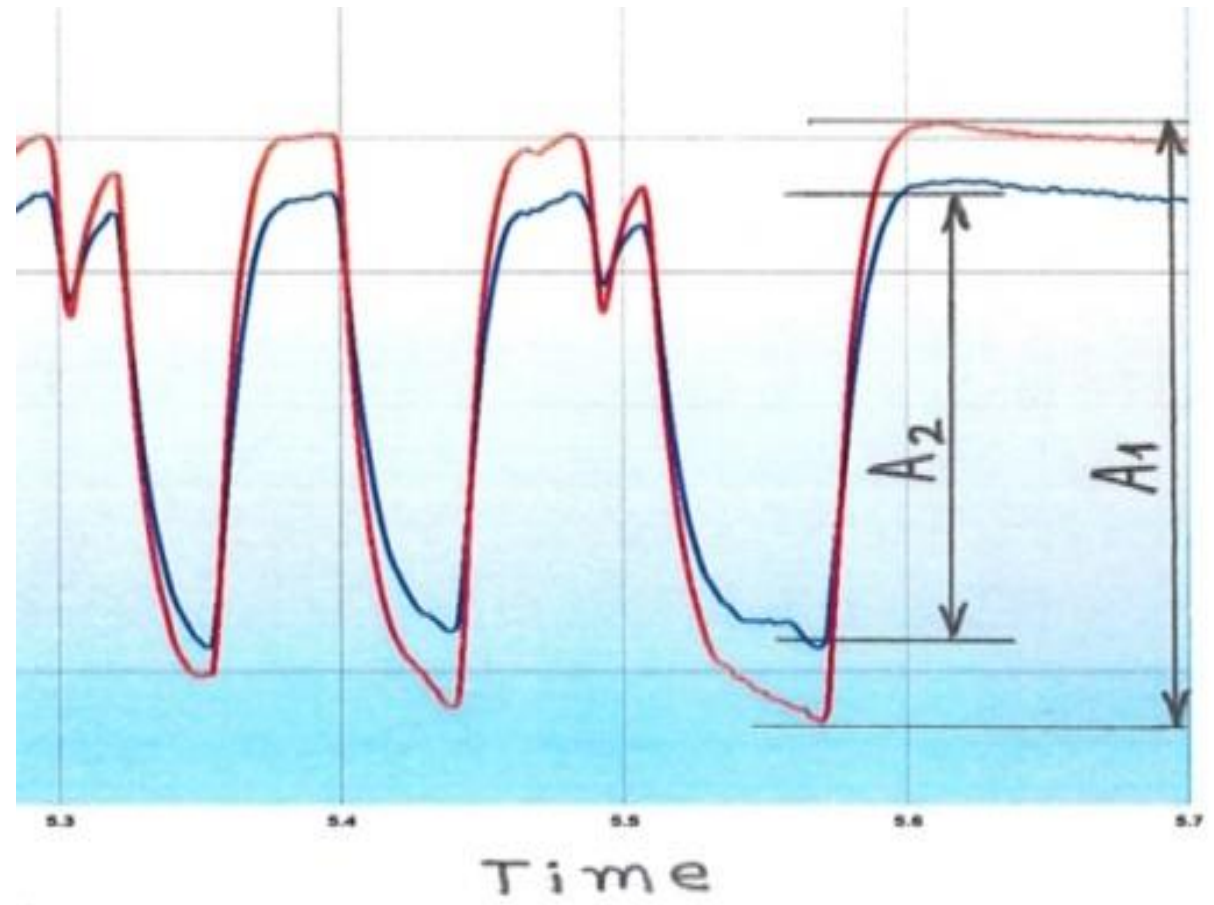

Figure 6. Amplitudes of respiration through left and right nostrils $-\mathrm{A}_{1}$ and $\mathrm{A}_{2}$.

Let us denote the amplitude of the recording through one nostril by $\mathrm{A}_{1}$ and the amplitude of the recording of the other nostril by $\mathrm{A}_{2}$. The amplitudes of the recording are proportional to the ratio between the amount of heat transferred during one inhalation and exhalation $\mathrm{Q}_{1}$ and $\mathrm{Q}_{2}$ from the volumes of inhaled and exhaled air $\mathrm{V}_{1}$ and $\mathrm{V}_{2}$ through both nostrils:

$\mathrm{A}_{1} / \mathrm{A}_{2} \sim \mathrm{Q}_{1} / \mathrm{Q}_{2} \sim \mathrm{V}_{1} / \mathrm{V}_{2}$

If we denote the hydraulic resistance of the nostrils by $\mathrm{R}=\Delta \mathrm{P} / \mathrm{J}$, where $\Delta \mathrm{P}$ is the respiratory pressure and $\mathrm{J}$ is the air flow equal to the volume of air $\mathrm{V}$ through each nostril during one respiratory cycle for time $t: J=V /$ t. Then the hydraulic resistance $(\mathrm{R})$ will be inversely proportional to the tidal volume through the nostrils:

$\mathrm{R}=$ Const. $/ \mathrm{V}$

As a final result we will get:

$\mathrm{A}_{1} / \mathrm{A}_{2}=\mathrm{V}_{1} / \mathrm{V}_{2}=\mathrm{R}_{1} / \mathrm{R}_{2}$

The conclusion is that the ratio between the amplitudes $\left(\mathrm{A}_{1} / \mathrm{A}_{2}\right)$ of the recordings is inversely proportional to the ratio of the hydraulic resistances $\quad\left(\mathrm{R}_{1} / \mathrm{R}_{2}\right)$ of the nostrils.

\section{MEASURABLE CHARACTERISTICS OF THE NASAL CYCLE}

The following characteristics of the nasal cycle can be determined from the records of respiration:
1. Cycle periodicity of the each nostril's dominance.

2. Correlation between the amplitude of the left (L) and right (R) nostrils $\left(A_{L}\right.$ and $\left.A_{R}\right)$.

3. Ratio $\left(R_{L R}\right)$ between the amplitudes of the two nostrils: $R_{L R}=A_{L} / A_{R}$.

4. Respiration laterality index (RLI):

$\operatorname{RLI}=\left(A_{L}-A_{R}\right) /\left(A_{L}+A_{R}\right)$, where $A_{L}$ and $A_{R}$ are the amplitude of the nostril airflow.

5. When characterizing the changes in the respiratory amplitude of only one nostril /( left or right ) at a time or for a period of time $\mathrm{T}$ can be used the characteristics:

a) $\mathrm{A}_{\mathrm{L}(\max )} / \mathrm{A}_{\mathrm{L}(\min )}$ ratio and $\mathrm{A}_{\mathrm{R}(\max )} /$ $A_{R(\min )}$ ratio

b) $\left(\mathrm{A}_{\mathrm{L}(\max )}-\mathrm{A}_{\mathrm{L}(\min )}\right) / \mathrm{T}$ ratio and $\left(A_{R(\max )}-A_{R(\min )}\right) / T$ ratio

Characteristic b) represents the rate at which the amplitude of nasal respiration changes

6. By calibrating the amplitude of the breath, by immersing the sensors in a liquid with a fixed temperature, the temperature range of the breathing air can be determined.

APPENDICES. Below on Figures 7-12 are given records of breathing through both nostrils, illustrating the possibilities of the method. 


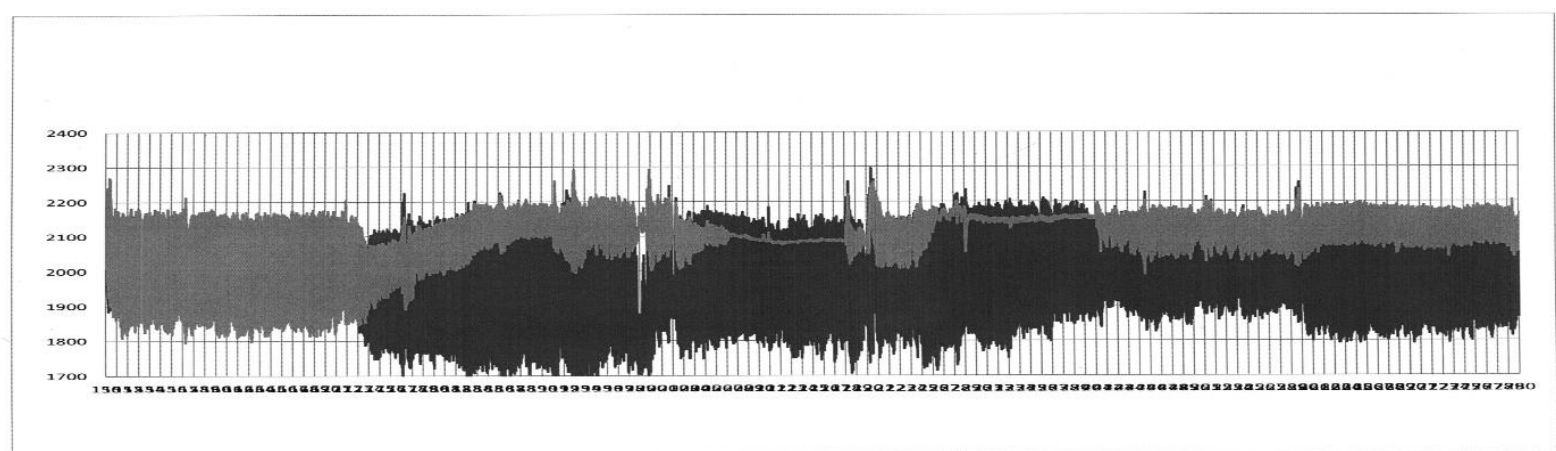

Figure 7. Compressed recording of breathing through the left (in gray) and right nostril (in black). The resistance of the left nostril varies against the background of the constant resistance of the right nostril.

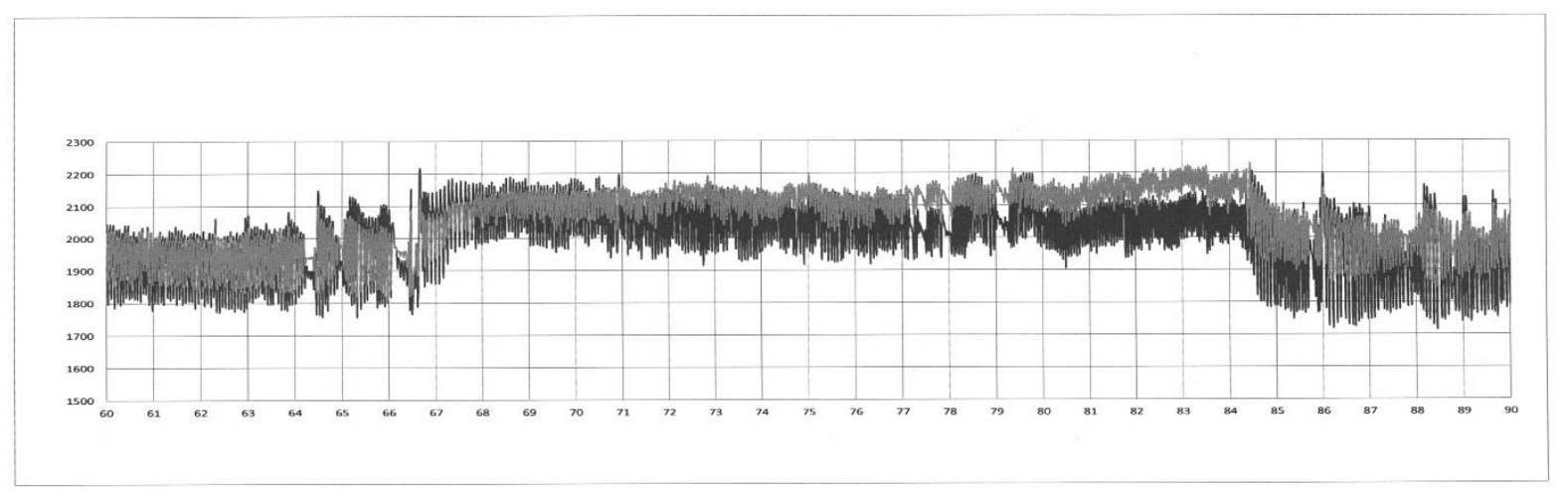

Figure 8. Compressed recording of breathing through the left (in gray) and right nostril ( in black). Approximately equal resistance of the left and right nostrils.

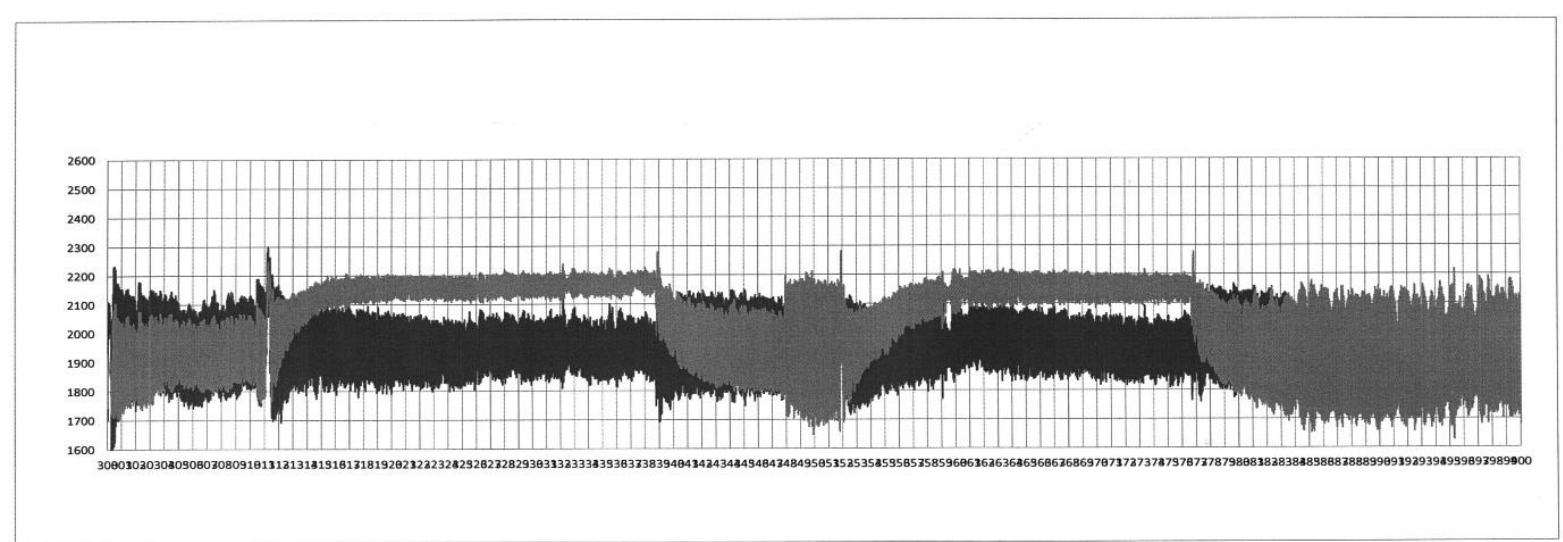

Figure 9. Compressed recording of breathing through the left (in gray) and right nostril (in black). Variation of resistance of the left and right nostrils.

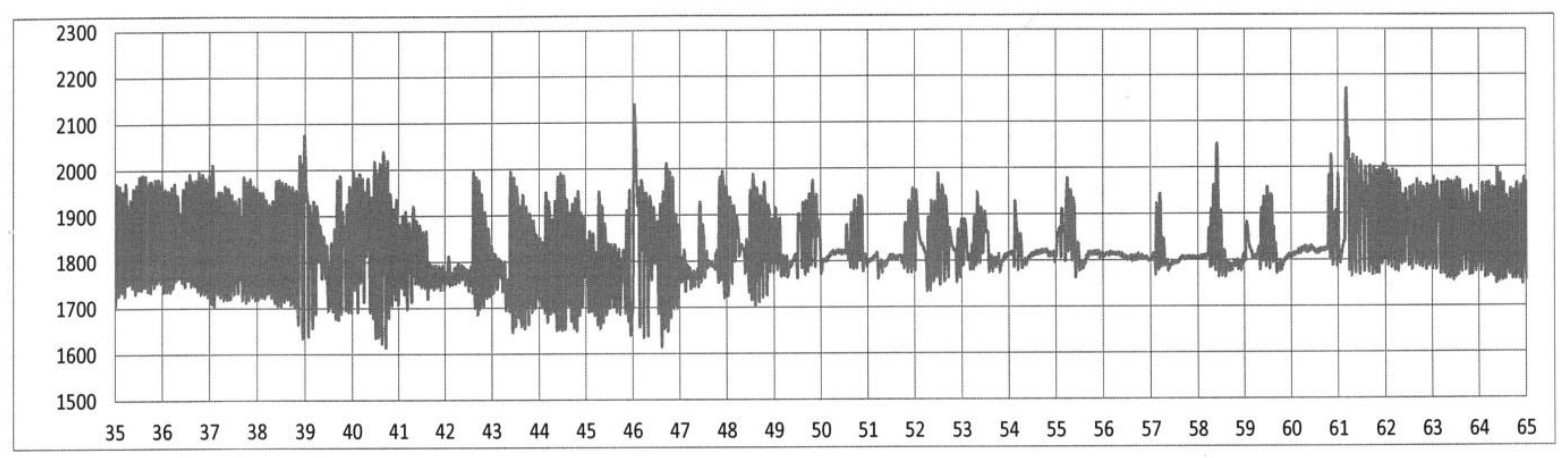

Figure 10. Record breathing through the left nostril during sleep. 


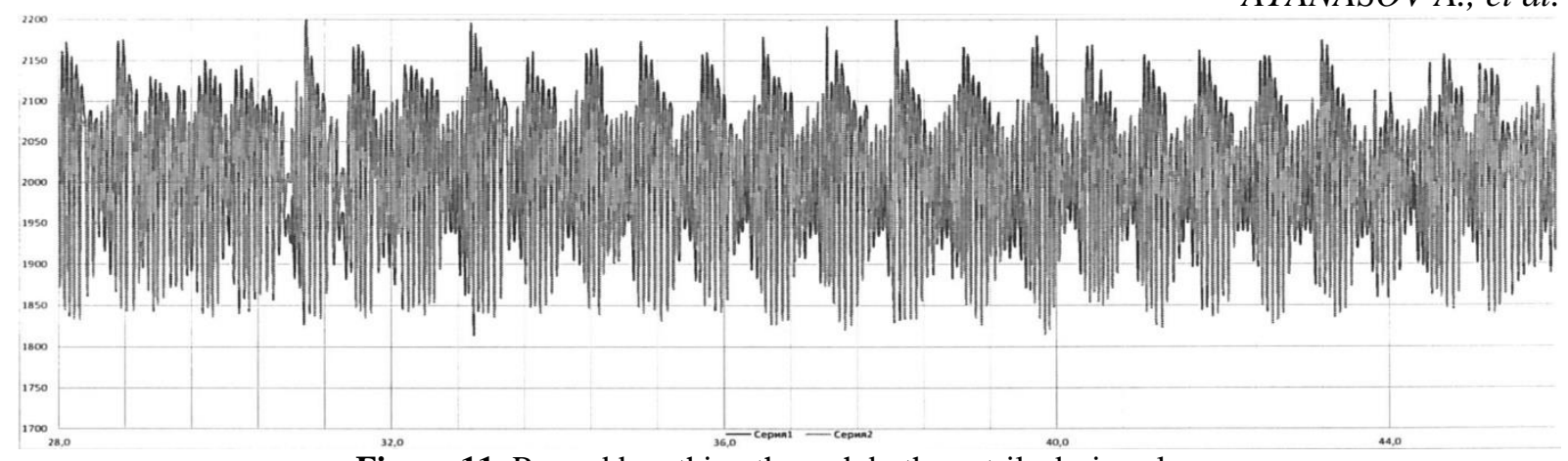

Figure 11. Record breathing through both nostrils during sleep.

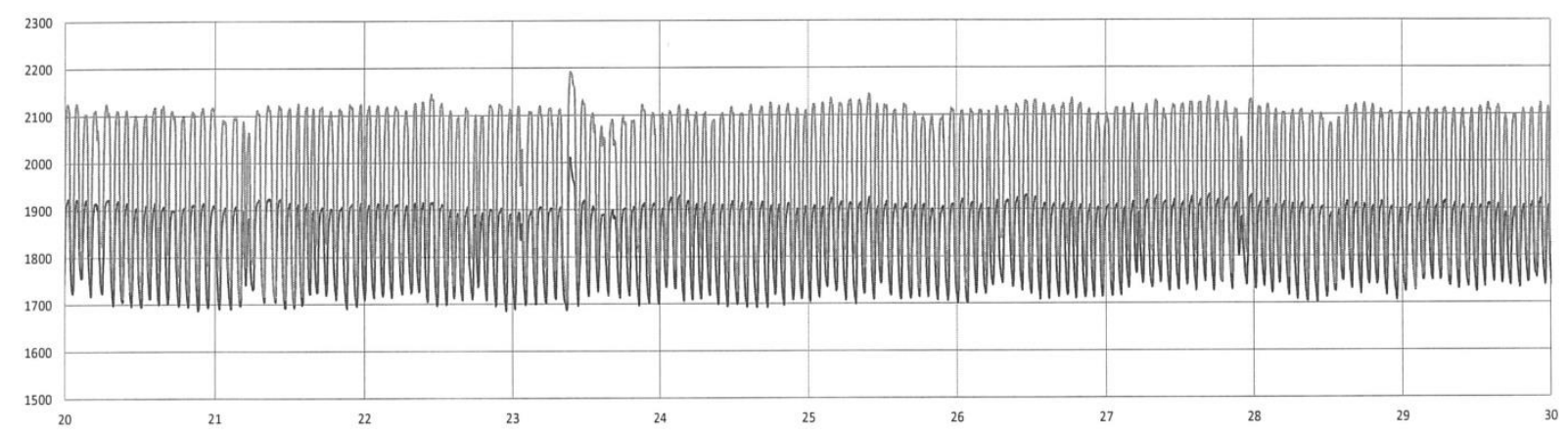

Figure 12. Record breathing through both nostrils during sleep.

\section{REFERENCES}

1. Hasegawa M., Kern E.B. The human nasal cycle. Mayo Clin. Proceed. 52: 28-34, 1977.

2. Hanif J., Jawad S.S.M., Eccles R. The nasal cycle in health and diseases. Clin. Otolaryngol., 25: 461-467, 2000.

3. Shannahoff-Khalsa D.S., Boyle M.R., Buebel M.E. The effect of unilateral forced nostril breathing on cognition. Int. J. Neurosci, 57: 239-249, 1991.

4. Block R.A., Arnott D.P., Quigley B. et al. Unilateral nostril breathing influences lateralized cognitive performance. Brain Cognition, 9:181190, 1989.

5. Werntz D.A., Bickford R.G., Bloom F.E. et al. Alternating cerebral hemispheric activity and the lateralization of autonomic nervous function. Human Neurobiol., 2: 39-43, 1983.

6. Atanasov A.T. Nasal cycle dilemma: nasal cycle is associated to brain Wake/REM states or is associated to consciousness state in them. Open Journal of Biophysics, 9(1): 1-9, 2019.

7. Atanasov A.T. Possible connection between the nasal cycle and consciousness. Trakia Journal of Sciences, 3: 198-203, 2018.
8. Stoksted

P.

Rhinometric measurements for determination of the nasal cycle. Acta Oto-Laryngologica, 43: 159-175, 1953.

9. Hanif J., Eccles P., Jawad S.S.M. Use of portable spirometer for studies of nasal cycle. American Journal of Rhinology and Allergy, 15(5): 303306, 2001.

10. Li Huang Z., Leong Ong K., Yi Goh S. Assesment of nasal cycle by acoustic rhinometry and rhinomanometry. Otolaryngol. Head Neck Surg, 128(4): 510-516, 2003.

11. Lang C.,Crützenmacher S., Mlynski B., Plonke S., Mlynski G.. Investigating the nasal cycle using endoscopy, rhinoresistometry and acoustic rhinometry. Laryngoscope , 113(2): 284-289, 2003.

12. Ohki M., Ogoshi T., Yuasa T., Kawano K., Kawano M.. Extended observation of the nasal cycle using a portable rhinoflowmeter. $J$. Otolaryngology 34 (5): 346-349, 2005.

13. Canter R.J. A non-invasive method using flexible liquid crystal thermology. Clinical Otolaryngology 11 (5): 329-336, 1986.

14. Szucs E., Kaufman L., Clement P.A.R. Nasal resistence - a reliable assessment of nasal patency? Clinical 
Otolaryngology\& Allied Sciences 20 (5): 390-395, 1955.

15. Fikuhara H.. Ultradian rhythms in the nasal cycle as measured by a new method. The Japanese Journal of Physiology, 66(6): 437-442, 1996.

16. Kumaran E.M.. Alternation in nasal cycle rhythm as an index of the diseased condition. Altered Physiological States. 2018-books google.com

17. Kahana-Zweig R., Geva-Sagiv M., Weissbroad A., Secundo L., Soroker N., Sobel N. Measuring and characterizing the human nasal cycle. PLoS ONE, 11(10), e0162918, 2016.

18. Atanasov A.T., Dimov P.D. Nasal and sleep cycle-possible synchronization during night sleep. Medical Hypotheses, 61(2): 275-277, 2003.

19. Atanasov A.T., Dimov P.D., Dimitrov B.D. Time periods in the nasal cycle during night sleep. Biological Rhythm Research, 34(4): 355-366, 2003.

20. Atanasov A.T. Length of periods in the nasal cycle during 24-hours registration. Open Journal of Biophysics, 4(3), ID: 47994, 2014.

21. Tahamiler R., Yener M., Canakcioglu S.. Detection of the nasl cycle in daily activity by remote evaluation of nasal sound. Arch. Otolaryngol. Neck Surg. 135(2): 137-142, 2009.

22. Klein R., Pilon D., Prosser S. Nasal airflow asymmetries and human performance. Biological Psychology, 23: 127-137, 1986.
ATANASOV A., et al.

23. Hanif J., Jawad S.S.M., Eccles R. The nasl cycle in health and disease. Clin. Otolaryngol., 25: 461-467, 2000.

24. Dane S., Balci N. Handedness, eyedness and nasal cycle in children with authism. International Journal of Develomental Neuroscience, DN1074, No.4, 2007.

25. Rice A., Eccles R. Nasal airflow and brain brain activity: is there a link? The Journal of Laryngology and Otology 130(9): 794-799, 2016.

26. D. Shannahoff-Khalsa D., Golshan S. Nasal cycle dominance and hallucinations in an adult schizophrenic female. Psychiatry Research 226: 289-294, 2015.

27. Atanasov AT. Stabilizing effect of yawning on nasal cycle. Global Neurology, 2020, 1(2), 07.

28. Kimura A., Chiba S., Capasso R., Yagi T., Ando Y.,Watanabe S., Moriyama $\mathrm{H}$. Phase of nasal cycle during sleep tends to be associated with sleep stage. Laryngoscope, 123 (8): 2050-2055, 2013.

29. Fisher J.G., de la Pena A., Garza G., Flickinger R. Evolution of methods of measuring respiratory activity. Sleep Research, 7: 288, 1978.

30. Lundqvist G.R., Pedersen O.F., Hilberg O., Nelsen B. Nasal reaction to changes In whole body temperature. Acta Otolaryngology (Stock), 113, 783-7: 1993. 